\title{
Interleukin-1 beta levels in gingival crevicular fluid in type 2 diabetes mellitus and adult periodontitis
}

\author{
Şule Bulut ${ }^{\S}$, Hakan Develioğlu ${ }^{\dagger}$, İbrahim Levent Taner ${ }^{\ddagger}$ and Ezel Berker* \\ §Department of Periodontology, Faculty of Dentistry, Başkent University, Ankara, Turkey \\ ${ }^{\dagger}$ Department of Periodontology, Faculty of Dentistry, Cumhuriyet University, Sivas, Tuekey \\ *Department of Periodontology, Faculty of Dentistry, Gazi University, Ankara, Turkey \\ *Department of Periodontology, Faculty of Dentistry, Hacettepe University, Ankara, Turkey
}

(Received 22 December 2000 and accepted 2 July 2001)

\begin{abstract}
Interleukin-1 beta (IL-1 $\beta$ ) is a potent bone-resorptive cytokine that also mediates soft-tissue destruction by stimulating prostaglandin production and inducing collagenase and other protease activity. The literature suggests that this substance may be an important mediator of attachment loss in human periodontitis, and indicates that IL-1 $\beta$ may be useful for locating sites of periodontal disease activity. There is some evidence that IL- $1 \beta$ is produced by cells of the periodontium, and that it can be detected in gingival crevicular fluid (GCF). Many factors are known to contribute to the destruction of periodontal tissue. One of the most important is immune deficiency in diabetes. The aim of this study was to measure and compare the concentration of IL-1 $\beta$ in the GCF of patients with noninsulin-dependent diabetes mellitus (Type 2 DM), otherwise healthy adults with periodontitis, and individuals with no periodontal disease in order to assess whether diabetes alters IL-1 $\beta$ levels. We also examined relationships between GCF levels and the clinical parameters of pocket depth, plaque index, and bleeding index in each group. Seventeen patients with Type 2 DM, 17 adult periodontitis patients (AP), and 17 healthy controls were selected. The levels of IL-1 $\beta$ in the GCF were quantified by ELISA. The mean IL$1 \beta$ concentrations in the Type $2 \mathrm{DM}, \mathrm{AP}$, and control groups were $200.1 \pm 65.34 \mathrm{pg} / \mu \mathrm{l}, 131.35 \pm 67.66 \mathrm{pg} / \mu \mathrm{l}$,
\end{abstract}

Correspondence to Dr. Şule BuLut, 2. Menekşe sokak no: 32/4 06440 Kizilay/ Ankara-Turkey

Tel: +903124180229

Fax: +903124250218

E-mail address: aslibulut@mail.koc.net.com and $80.0 \pm 36.08 \mathrm{pg} / \mu \mathrm{l}$, respectively. The levels in the diabetic patients were significantly higher than those in the AP and control subjects. There were no significant correlations between IL- $1 \beta$ level and any of the clinical data parameters for each group. We believe that the macrophages may over produce IL- $\beta$ in Type $2 \mathrm{DM}$ and increased IL- $1 \beta$ levels in diabetic patients could be linked to altered immune function. (J. Oral Sci. 43, 171177, 2001)

Key words: interleukin-1 beta; diabetes mellitus; gingival crevicular fluid; periodontal disease

\section{Introduction}

Periodontal disease destroys the tissues that support the teeth. The destructive process can involve the gingival ligament (gingivitis) and/or the periodontal ligament and bone that surround and support the teeth (periodontitis). Although the pathogenesis of periodontal lesions is poorly understood, recent studies indicate that dental plaque formation and host immune response are both important factors (1).

Interleukin- 1 beta (IL- $1 \beta$ is a pro-inflammatory multifunctional cytokine that is produced in large amounts by macrophage-monocytes and may play a significant role in periodontal disease (2). IL- $1 \beta$ is one of the factors known to stimulate bone resorption and the secretion of proteinases, and it may be involved in the attachment loss and bone resorption that are characteristic of periodontitis (3). Many reports have indicated that IL- $1 \beta$ activity is greater in the gingival crevicular fluid (GCF) at inflamed 
Table 1 Mean values for the clinical findings in the entire dentition, by patient group

\begin{tabular}{|l|l|l|l|l|l|}
\hline & $\begin{array}{l}\text { Probing } \\
\text { Depth (mm) }\end{array}$ & Plaque Index $(+)$ & Plaque Index (-) & Bleeding Index (+) & Bleeding Index (-) \\
\hline TYPE 2 DM & $3.84 \pm 0.84$ & $66.17 \pm 27.90$ & $74 \pm 30.59$ & $82.35 \pm 26.56$ & $57.88 \pm 27.01$ \\
\hline AP & $3.51 \pm 0.80$ & $88.70 \pm 6.58 *$ & $70.82 \pm 12.03$ & $66.35 \pm 15.60 *$ & $89.41 \pm 6.88 *$ \\
\hline CONTROLS & $1.26 \pm 0.26 *$ & $63.70 \pm 11.60$ & $92.23 \pm 9.78 *$ & $89.11 \pm 7.67$ & $51.70 \pm 9.88$ \\
\hline
\end{tabular}

* Significant correlation $(P<0.01)$

DM ( Diabetes Mellitus) AP (Adult Periodontitis)

gingival sites than in the GCF at sites that are not inflamed (4-7).

Diabetes mellitus (DM) describes a heterogeneous group of disorders with the common characteristic of altered glucose tolerance or impaired lipid and carbohydrate metabolism. The condition develops because of either deficient insulin production or impaired insulin metabolism. On the basis of these etiologies, DM is categorized as two main types: Type 1 (formerly known as insulin-dependent diabetes mellitus) and Type 2 (formerly known as noninsulin-dependent diabetes). Type $2 \mathrm{DM}$ patients are often obese, and their glucose intolerance can usually be treated with diet and body weight control or with oral hypoglycemic agents. Both forms of DM are associated with many systemic complications, including microangiopathy, neuropathy, nephropathy, microvascular disease, and delayed wound healing. DM is an important systemic predisposing factor in the etiology of inflammatory periodontal disease (8). Clinical and epidemiological studies have shown that diabetics patients have a higher incidence of and more severe gingivitis and periodontitis than individuals in the general population $(9,10)$. The mechanisms behind DM have not been clearly established, but recent studies in diabetic patients have suggested that periodontitis begins at the cellular and molecular level, and is related to mechanisms and mediators of the host response to tissue injury. In addition, the bacteria that colonize plaque are a continuous source of tissue-damaging toxins (11).

The latest studies have examined GCF IL- $1 \beta$ levels, monocytic secretion, and the clinical presentation of Type 1 DM patients and non-diabetic patients with varying degrees of periodontal disease (12-14). The aim of this study was to evaluate the role of IL- $1 \beta$ in the pathogenesis of Type 2 DM. We compared GCF IL- $1 \beta$ levels in patients with Type 2 DM, otherwise healthy patients with adult periodontitis (AP), and healthy individuals with no periodontal disease, and tested correlations between these concentrations and various clinical parameters in each group.

\section{Materials and Methods}

\section{Patient selection}

We collected data from 17 patients with AP (10 males and 7 females of mean age 42.5 years) and 17 adults with Type 2 DM ( 8 males and 9 females of mean age 52.5 years) who were referred to the Department of Periodontology in the Faculty of Dentistry at Gazi University. We also recruited 17 systemically and periodontally healthy subjects as the control group (12 males and 5 females of mean age 45.3 years).

AP was diagnosed clinically and radiographically according to patient age, pattern of bone loss, and existing bacterial plaque and calculus. The criteria for diagnosis were based on those outlined by Page and Schroeder (15). All the Type $2 \mathrm{DM}$ patients were under the medical care of the Department of Endocrinology, and Type 2 DM was diagnosed by a physician. Based on intraoral examination, 17 of these diabetic patients with periodontitis were selected for the study.

\section{Clinical data}

The clinical parameters studied in each patient were probing depth (PD), plaque index (PI), and bleeding index 
Table 2 Mean values for the clinical findings in the GCF sampling area, by patient group

\begin{tabular}{|l|l|l|l|l|l|}
\hline & Probing Depth $(\mathrm{mm})$ & Plaque Index $(+)$ & Plaque Index (-) & Bleeding Index (+) & Bleeding Index (-) \\
\hline TYPE 2 DM & $3.51 \pm 1.08$ & $14.82 \pm 16.38$ & $21.52 \pm 15.28$ & $21.88 \pm 8.16$ & $10.0 \pm 6.29$ \\
\hline AP & $4.40 \pm 0.92$ & $16.29 \pm 4.23 *$ & $17.94 \pm 4.93$ & $17.29 \pm 8.99^{*}$ & $16.88 \pm 2.89 *$ \\
\hline CONTROL & $1.17 \pm 0.8$ & $8.52 \pm 1.50$ & $24.29 \pm 4.83$ & $22.47 \pm 3.77$ & $8.23 \pm 1.64$ \\
\hline
\end{tabular}

* Significant correlation $(P<0.01)$

DM (Diabetes Mellitus) AP (Adult Periodontitis)

(BI). The presence of plaque on the tooth surfaces was evaluated with a periodontal probe. Patients with plaque scored $(+)$ and those with no plaque accumulation were labeled ( - ). Similarly, bleeding after gentle manipulation with a periodontal probe was assessed as $(+)$ and lack of bleeding was labeled ( - ). The scores were recorded for the area where GCF was sampled and for the dentition as a whole.

\section{Gingival crevicular fluid sampling}

Gingival crevicular fluid was collected according to the method of Rudin et al. (16), and the clinical data were recorded after the GCF sampling. To avoid contamination with saliva, we focused on the anterior maxillary teeth, and specifically those that had at least one site with a probing depth of $5 \mathrm{~mm}$ (6). The experimental area was isolated with cotton rolls and was gently air-dried. An electronic scale was used to weigh all materials. Standardized $(2 \times 10$ $\mathrm{mm})$ pre-weighed filter-paper strips were inserted into the buccal crevice to the level of $1 \mathrm{~mm}$ below the gingival margin, and were kept in place for 3 minutes. The strips with absorbed GCF were then placed in pre-weighed, scaled, plastic tubes. Strips that were contaminated with saliva or blood were excluded from the sampling group. The strips were weighed before and immediately after the collection, within a sealed microcentrifuge plastic tube. The difference between the two weighings gave the volume of fluid collected, assuming a specific gravity of approximately $1(5,17)$. Each sample was stored at $-70^{\circ} \mathrm{C}$ until ELISA was performed.

\section{Cytokine analysis}

To extract the GCF, we added $250 \mu 1$ of Hank's buffered salt solution containing $0.5 \%$ bovine serum albumin to each tube, and then mixed the tube contents. The IL- $1 \beta$ in the GCF was assayed by an ELISA kit (Quantikine, R\&D Systems, Inc. Minneapolis) that included a calibration curve with measured IL-1 $\beta$ standards (range, 3.9-250 $\mathrm{pg} / \mathrm{\mu l}$ ). Each sample was studied in duplicate. One hundredmicroliter aliquots of GCF were pipetted into a 96-well plate, and the assay was carried out as described by the manufacturer. We read the peroxidase substrate color reaction at a wavelength of $490 \mathrm{~nm}$ in a Titertek spectrophotometer. The IL- $1 \beta$ level in each sample was expressed in $\mathrm{pg} / \mu \mathrm{l}(5,17)$.

\section{Statistical analysis}

The differences among the groups' clinical parameters and GCF IL- $1 \beta$ levels were tested using one-way analysis of variance and the Duncan test. Within each group, we used Pearson's product moment correlation coefficient to test relationships between mean IL- $1 \beta$ level and each clinical value (at the sampling area and for the entire dentition).

\section{Results}

Tables 1 and 2 list the clinical data for the entire dentition and the GCF sampling area, respectively. Although pocket depth and PI(-) scores were similar in the AP and Type 2 DM groups, the $\mathrm{BI}(-), \mathrm{BI}(+)$, and $\mathrm{PI}(+)$ scores for the two groups differed significantly in the GCF sampling area and the entire dentition $(\mathrm{P}<0.01$ in all cases).

The mean GCF IL- $1 \beta$ levels and GCF volumes are 
Table 3 Mean IL- $1 \beta$ concentration in GCF and the mean quantity of GCF collected for each group

\begin{tabular}{|l|l|l|}
\hline & & \\
& IL-1 $\beta$ concentration $\mathrm{pg} / \mu \mathrm{l}$ & Quantity of GCF $(\mu \mathrm{l})$ \\
\hline TYPE 2 DM & $200.17 \pm 65.34 *$ & $4.18 \pm 2.65$ \\
\hline AP & & $3.94 \pm 1.25$ \\
\hline CONTROL & $131.35 \pm 67.66$ & \\
\hline
\end{tabular}

* Statistical differences were found between two disease groups and statistical differences were found between healthy and diseased groups for IL- $1 \beta$ concentration $(P<0.01)$. No statistical differences were found between the two disease group and statistical differences were found between healthy and diseased groups for GCF volumes $(P<0.01)$.

DM ( Diabetes Mellitus) AP (Adult Periodontitis)

presented in Table 3. The mean GCF volume was $4.18 \pm$ $2.65 \mu \mathrm{l}$ in Type $2 \mathrm{DM}$ patients, $3.94 \pm 1.25 \mu \mathrm{l}$ in AP patients, and $1.94 \pm 0.75 \mu \mathrm{l}$ in controls. The Type $2 \mathrm{DM}$ GCF volume was slightly, but not significantly, higher than that in the other diseased group. Statistical differences were found between diseased groups and healthy group from the stand point of GCF volumes $(P<0.01)$.

The mean IL- $1 \beta$ concentrations in the Type $2 \mathrm{DM}, \mathrm{AP}$, and control groups were $200.17 \pm 65.34 \mathrm{pg} / \mathrm{\mu l}, 131.35 \pm$ $67.66 \mathrm{pg} / \mu \mathrm{l}$, and $80.0 \pm 36.08 \mathrm{pg} / \mu \mathrm{l}$, respectively. The level in the control group differed significantly from the concentrations in the diseased groups $(P<0.01)$, and the mean IL- $1 \beta$ level in the Type 2 DM patients was significantly higher than the level in the AP group $(P<$ $0.01)$.

There were no significant correlations between IL- $1 \beta$ concentration and the clinical parameters in any of the groups.

\section{Discussion}

Many studies have shown that the prevalence of periodontitis is higher in diabetic patients than in nondiabetics, and that DM increases the risk of severe periodontitis $(11,18,19)$. Although the detailed pathogenesis of periodontitis in diabetic patients is not known, a number of pathologic features of this disease are consistent with increased risk for periodontitis. Impaired neutrophil function, microvascular alterations that partially block leukocyte and plasma protein access to the periodontium, and altered collagen metabolism (which involves increased collagenase activity, decreased collagen synthesis and reduced bone matrix formation) may all predispose the diabetic patient to periodontal breakdown (20). Also, the GCF of these patients is known to contain elevated glucose levels (21), and it has been suggested that glucose in gingival fluid may alter plaque microflora and promote the development of periodontal disease and dental caries (22).

$\mathrm{IL}-1 \beta$ is a pro-inflammatory multifunctional cytokine that is released by monocytes and macrophages. Its many biological activities include the induction of inflammatory cell migration to infected sites, stimulation of bone resorption, and stimulation of PGE2 production. It also causes the release of matrix metalloproteinase, which degrades proteins of the extracellular matrix and participates in many facets of the immune response. Numerous studies have suggested that levels of IL- $1 \beta$ are higher in both tissue and GCF from inflamed periodontal regions than at healthy sites (3).

Recently, many immunological and microbiological investigations have focused on Type $1 \mathrm{DM}$ patients with periodontal disease (23); however, we focused specifically on IL- $1 \beta$ levels in GCF from Type 2 DM patients with periodontitis. The clinical setting of diabetes presents an interesting model for studying periodontal disease because delayed wound healing and periodontitis are two major features of DM. In the present study, it was hoped that comparison of IL- $1 \beta$ levels in non-diabetic patients with AP to levels in Type 2 DM patients with periodontitis would reveal some clues about the pathogenesis of periodontitis. The results showed that Type $2 \mathrm{DM}$ patients with periodontitis had higher GCF IL- $1 \beta$ levels than individuals with AP. 
Several factors are known to affect the concentration of this mediator in periodontal pockets in Type $2 \mathrm{DM}$. Enhanced local production of IL- $1 \beta$ in this patient group may be a factor of individual immunological differences, microbial composition of dental plaque, and systemic problems. In a hyperglycemic environment, numerous proteins, including collagen, undergo a non-enzymatic glycosylation process to form advanced glycation endproducts (AGEs). Monocytes, macrophages, and endothelial cells possess high-affinity receptors for AGEs (24-26). The binding of AGEs to receptors on macrophages may induce a hyperresponsive cellular state, resulting in increased secretion of IL-1, insulin-like growth factor and tumor necrosis factor (TNF)- $\alpha$, while binding of AGEs to endothelial cells results in procoagulatory changes that induce focal thrombosis and vasoconstriction. The finding of higher levels of IL- $1 \beta$ in Type 2 DM may be linked to the AGE concentration in these patients' crevicular fluid. Salvi et al. (13) found that monocytes from diabetic patients produce significantly greater amounts of TNF- $\alpha$, IL- $1 \beta$, and $\mathrm{PGE}_{2}$ in vitro than monocytes from non-diabetic controls. Clinically, diabetic subjects with periodontitis have significantly higher GCF levels of both IL- $1 \beta$ and $\mathrm{PGE}_{2}$ than non-diabetic controls matched for periodontal disease severity.

In another experimental study, Doxey et al. (14) measured platelet-derived growth factor $b$ (PDGF-b), IL-1 $\beta$, transforming growth factor-beta, (TGF- $\beta$ and tumor necrosis factor-alpha (TNF- $\alpha$ ) in rats with diabetes, and compared the results to findings in non-diabetic rats with periodontitis. Diabetes alone did not alter the gingival cytokine profile for PDGF-b, IL- $1 \beta$, TGF- $\beta$ and TNF- $\alpha$, but PDGF- $b$ and IL- $1 \beta$ were significantly higher in the nondiabetic rats with periodontitis. The report suggested that diabetes-induced metabolic changes do not affect gingival cytokine levels, but that these alterations do alter the normal host response to periodontitis by blocking the periodontitis-induced increase in PDGF-b and IL- $1 \beta$.

We did not examine microbiological parameters in this study, but it is possible that the higher IL- $1 \beta$ levels in Type 2 DM patients may be linked to differences and complexities of the host response to local microbiological challenges. The elevated IL- $1 \beta$ levels in Type 2 DM may also be the result of a systemically upregulated monocytic hypersecretory $(\mathrm{MO}+)$ trait. Pro-inflammatory cytokines, such as IL- $1 \beta$, are necessary components of the initial destructive phase of tissue turnover. There are many conflicting reports on diabetic monocyte cytokine responses. Some investigators have reported upregulation of monocytic IL- $1 \beta$ in diabetic patients (27), while others have reported significantly lower levels of IL- $1 \beta$, IL-16, and TNF- $\alpha$ in diabetics (28). Upregulation of IL- $1 \beta$ synthesis may be related to metabolic abnormalities of the diabetic condition (hyperlipidemia and increased AGE production). Such a change may lead to excessive production of pro-inflammatory cytokines by macrophages, thus increasing the rate and degree of tissue destruction (29).

Diabetes mellitus is a significant risk factor for more serious periodontal disease because these individuals mount a more intense inflammatory reaction to bacteria than non-diabetics. Moreover, Zambon et al. (30) stated that biochemical changes and increased amounts of glucose in GCF could provide good growth conditions for facultative or anaerobic microorganisms. Microbiological and immunological studies have suggested that Prevotella intermedia, Campylobacter rectus, and Porphymonas gingivalis play important roles in the periodontitis seen in Type 2 DM.

We found no significant associations between IL-1 $\beta$ level and the various clinical findings in each group. The lack of a relationship with pocket depth is not surprising since this reflects the cumulative history of periodontal disease and is not necessarily an indicator of the current state. Disease action at each individual pocket varies with time, and ranges from inactivity to high activity, regardless of pocket depth. (31). Bleeding on probing indicates an inflamed periodontal pocket, not gingival inflammation (32). On the other hand, vascular changes are caused by many factors, and clearly do not depend on IL- $1 \beta$ alone. Plaque index is an indicator of current oral hygiene. A low PI suggests good hygiene, but does not give any information on inflammation. In keeping with our results, Wilton et al. (5) found no statistically significant correlations between IL- $1 \beta$ level and PI, BI, and pocket depth. They suggested that above-normal IL- $1 \beta$ in GCF from numerous sites is evidence of previous periodontal destruction.

In addition, the inadequacy of the clinical indices to reflect the changes occuring in the periodontium during inflammatory processes and the time interval between the reflection of the histopathological events and the clinical appearance may be the reason we could not find any relationship between the clinical parameters and GCF IL$1 \beta$ levels.

Although the level of periodontal breakdown was similar in our diabetic and non-diabetic subjects with periodontal disease, bleeding index and IL- $1 \beta$ levels were higher in the Type $2 \mathrm{DM}$ patients than in their AP counterparts. This disparity can be attributed to differences in local immune response between two disease groups. We suggest that Type $2 \mathrm{DM}$ is a significant risk factor for more severe periodontal disease because the diabetic patient mounts a more intense 
inflammatory reaction to bacteria than the non-diabetic. To better understand the local immune response and pathogenesis of periodontal breakdown in Type $2 \mathrm{DM}$, it will be necessary to conduct further studies on relationships between microorganisms and other cytokines in this patient group.

\section{References}

1. The American Academy of Periodontology (1999) The pathogenesis of periodontal diseases. J. Periodontol. 70, 457-470

2. Matsuki, Y., Yamamoto, T. and Hora, K. (1991) Interleukin-1 mRNA-expressing macrophages in human chronically inflamed gingival tissues. Am. J. Pathol. 138, 1299-1305

3. Tatakis, D.N. (1993) Interleukin-1 and bone metabolism: a review. J. Periodontol. 64, 416-431

4. Masada, M.P., Persson, R., Kenney, J.S., Lee, S.W., Page, R.C. and Allison, A.C. (1990) Measurement of interleukin- 1 alfa and -1 beta in gingival crevicular fluid: implications for the pathogenesis of periodontal disease. J. Periodontal. Res. 25, 156-163

5. Wilton, J.M.A., Bampton, J.L.M., Griffiths, G.S., Curtis, M.A., Life, J.S., Johnson, N.W., Powell, J.R., Harrap, G.J. and Critchley, P. (1992) Interleukin1 beta (IL-1 $\beta$ ) levels in gingival crevicular fluid from adults with previous evidence of destructive periodontitis. A cross sectional study. J. Clin. Periodontol. 19, 53-57

6. Preiss, D.S. and Meyle, J. (1994) Interleukin-1 $\beta$ concentration of gingival crevicular fluid. J. Periodontol. 65, 423-428

7. Yavuzyilmaz, E., Yamalik N., Bulut, Ş., Özen, S., Ersoy, F. and Saatçi, Ü. (1995) The gingival crevicular fluid interleukin-1 beta and tumor necrosis factor-alpha levels in patients with rapidly progressive periodontitis. Aust. Dent. J. 40, 46-49

8. Löe, H. (1993) Periodontal disease. The sixth complication of diabetes mellitus. Diabetes Care 16, 329-334

9. Pennel, B.M. and Keagle, J.G. (1977) Predisposing factors in the etiology of chronic inflammatory periodontal disease. J. Periodontol. 48, 517-532

10. The American Academy of Periodontology (1999) Diabetes and periodontal diseases. J. Periodontol. 70, 935-949

11. Genco, R.J., Wilson, M.E. and De Nardin, E. (1990) Periodontal complications and neutrophil abnormalities. In contemporary periodontics. Genco, R.J., Goldman, H.M. and Cohen, D.W. eds., The C.V. Mosby, St. Louis, 212-217
12. Salvi, G.E., Yalda, B., Collins, J.G., Jones, B.H., Smith, F.W., Arnold, R.R. and Offenbacher, S. (1997) Inflammatory mediator response as a potential risk marker for periodontal disease in insulindependent diabetes mellitus patients. J. Periodontol. $68,127-135$

13. Salvi, G.E., Beck, J.D. and Offenbacher, S. (1998) PGE2, IL-1 beta, and TNF-alpha responses in diabetics as modifiers of periodontal disease expression. Ann. Periodontol. 3, 40-50

14. Doxey, D.L., Cutler, C.W. and Iacopino, A.M. (1998) Diabetes prevents periodontitis-induced increases in gingival platelet derived growth factor-B and interleukin-1 beta in a rat model. J. Periodontol. 69 , 113-119

15. Page, R.C. and Schroeder, H.E. (1976) Pathogenesis of inflammatory periodontal disease. A summary current work. Lab. Invest. 34, 235-249

16. Rudin, H.J., Overdiek, H.F. and Rateitschak, K.H. (1970) Correlation between sulcus fluid rate and clinical and histological inflammation of the marginal gingiva. Helv. Odontl. Acta 14, 21-26

17. Giannopoulou, C., Andersen, E., Demeurisse, C. and Cimasoni, G. (1992) Neutrophil elastase and its inhibitors in human gingival crevicular fluid during experimental gingivitis. J. Dent. Res. 71, 359-363

18. Emrich, L.J., Shlossman, M. and Genco, R.J. (1991) Periodontal disease in non-insulin-dependent diabetes mellitus. J. Periodontol. 62, 123-131

19. Miller, L.S., Manwell, M.A., Newbold,D., Reding, M.E., Rasheed, A., Blodgett, J. and Kornman, K.S. (1992) The relationship between reduction in periodontal inflammation and diabetes control: a report of 9 cases. J. Periodontol. 63, 843-848

20. Cutler, C.W., Eke, P., Arnold, R.R. and Van Dyke, T.E. (1991) Defective neutrophil function in an insulin-dependent diabetes-mellitus patient. A case report. J. Periodontol. 62, 394-401

21. Ficara, A.J., Levin, M.P., Grower, M.F. and Kramer, G.D. (1975) A comparision of the glucose and protein content of gingival fluid from diabetics and nondiabetics. J. Periodontal Res. 10, 171-175

22. Hallmon, W.W. and Mealey, B.L. (1992) Implications of diabetes mellitus and periodontal disease. Diabetes Educ. 18, 310-315

23. Anil, S., Remani, P., Vijayakumar, T. and Hari, S. (1990) Cell-mediated and humoral immune responses in diabetic patients with periodontitis. Oral Surg. Oral Med. Oral Pathol. 70, 44-48

24. Brownlee, M. (1994) Lilly Lecture 1993. Glycation and diabetic complications. Diabetes $43,836-841$ 
25. Esposito, C., Gerlach, H., Brett, J., Stern, D. and Vlassara, H. (1989) Endothelial receptor-mediated binding of glucose-modified albumin is associated with increased monolayer permeability and modulation of cell surface coagulant properties. J. Exp. Med. 170, 1387-1407

26. Kirstein, M., Aston, C., Hintz, R. and Vlassara, H. (1992) Receptor-specific induction of insulin-like growth factor I in human monocytes by advanced glycosylation end product-modified proteins. J. Clin. Invest. 90, 439-446

27. Schmidt, A.M., Yan, S.D., Brett, J., Mora, R., Nowygrod,R. and Stern, D. (1993). Regulation of human mononuclear phagocyte migration by cellsurface-binding proteins for advanced glycation end products. J. Clin. Invest. 92, 2155-2168

28. Ohno,Y., Aoki, N. and Nishimura, A. (1993) In vitro production of interleukin-1, interleukin-6, and tumor necrosis factor-alpha in insulin-dependent diabetes mellitus. J. Clin. Endocrinol. Metab. 77, 1072-1077

29. Iacopino, A.M. (1995) Diabetic periodontitis: possible lipid-induced defect in tissue repair through alteration of macrophage phenotype and function. Oral Dis. 1, 214-229

30. Zambon, J.J., Reynolds, H., Fisher, J.G., Shlossman, M., Dunford, R. and Genco, R.J. (1988) Microbiological and immunological studies of adult periodontitis in patients with noninsulin-dependent diabetes mellitus. J. Periodontol. 59, 23-31

31. Socransky, S.S., Haffajee, A.D., Goodson, J.M. and Lindhe, J. (1984) New concepts of destructive periodontal disease. J. Clin . Periodontol. 11, 21-32

32. van der Velden, U. (1980) Influence of periodontal health on probing depth and bleeding tendency. J. Clin. Periodontol. 7, 129-139 